\title{
Should we be pining for the fjords? Probation, debt and desistance in Norway
}

John Todd-Kvam provides an overview of his doctoral research which explored the ways in which people in Norway desist from offending, experience probation and cope with the consequences of what he terms 'punishment debt'.
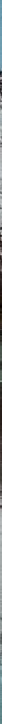
Norwegian prisons have played host to many visiting researchers, journalists, practitioners and documentary filmmakers, with prisons like Halden and the island-prison of Bastøy receiving almost celebrity status. However, until recently we had relatively little research knowledge about life on probation or after punishment in Norway. My recently-completed $\mathrm{PhD}$ project aimed to help map out some of this territory through a qualitative, multi-level study of political discourse, reintegration and resettlement practice, and the lived experience of desistance. By 'zooming in' from political discourse through practice to desister experience, I aimed to provide insight into both the context in which desistance takes place as well as the process itself. The project involved fieldwork at the Red Cross-run Network House, described as "Norway's first re-entry centre', where those seeking to move away from crime can access education, training, social activities, help in finding employment, one-to-one contact with a volunteer support contact and debt advice caseworkers. I also interviewed probation caseworkers in Oslo and people who identified themselves as desisting from crime.

Perhaps one of the project's most important contributions is shedding light on so-called

'punishment debt' (Todd-Kvam 2019). The key

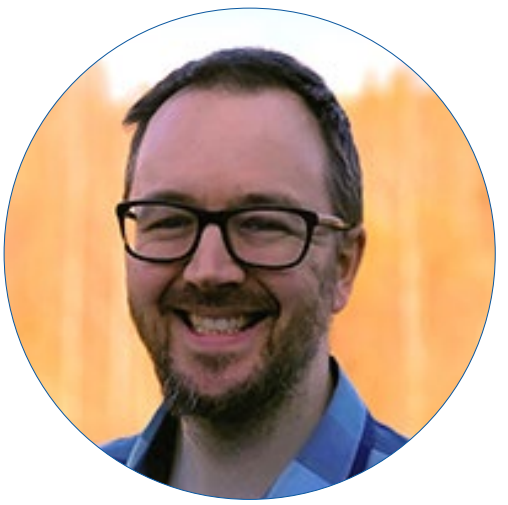

John Todd-Kvam

Postdoctoral Researcher

Norwegian Centre for Addiction Research, University of Oslo

sources of this debt are compensation, fines and confiscation, with a study of prisoners' living conditions finding that over $80 \%$ of prisoners in Norway had debt, with $37 \%$ having debt from being sentenced to pay compensation, $26 \%$ from unpaid fines and $17 \%$ with debt to private persons (including illegal debt such as drug debts) (Revold 2015). As an illustration of this, the following chart shows how state income from financial penalties have increased whilst reported crime has decreased.

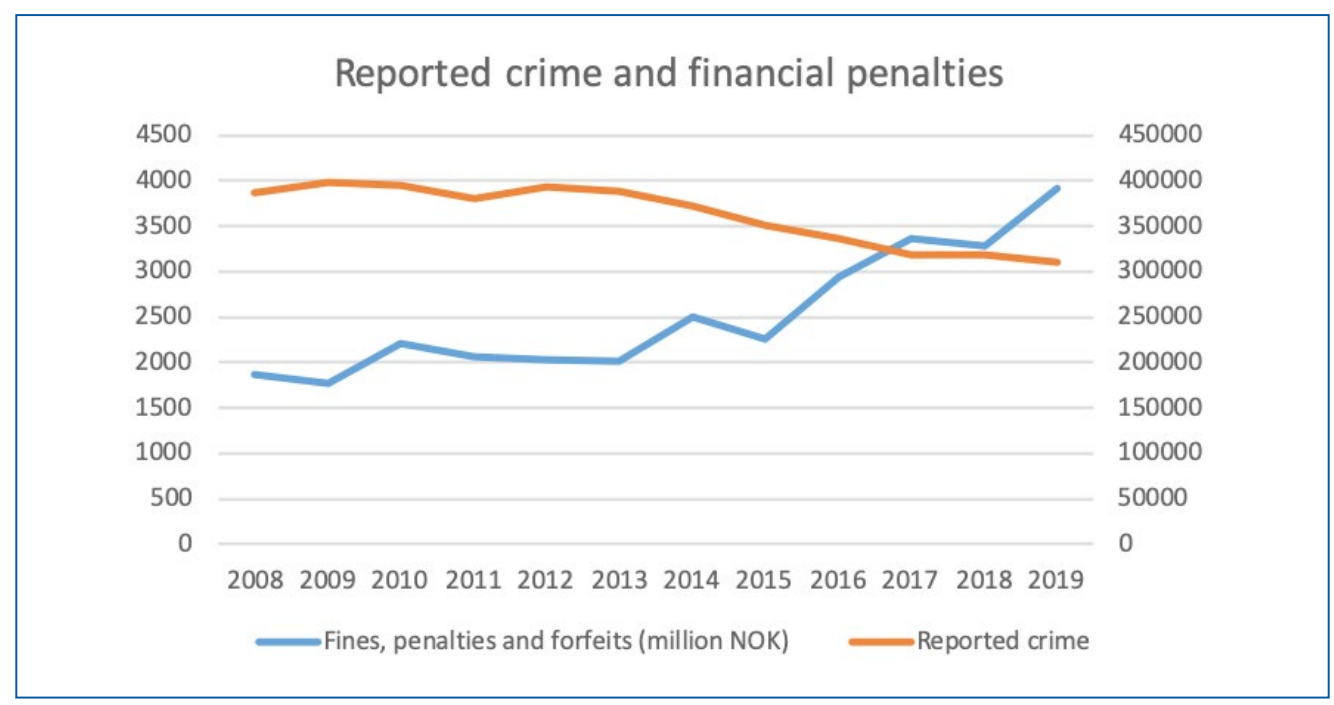

Figure 1: Reported crime and financial penalties (data sources: Statistics Norway 2021a, 2021b) 
The state is empowered to make salary deductions and confiscate assets in order to service this debt. Interviews with both probation staff and desisters themselves raised four particularly negative aspects of living with 'punishment debt'. These are:

1. The fear of getting started in paying off the debt - it can feel like an impossible task.

2. A sense of unfairness and double punishment - society expects people to live normally and get a job, but treats them abnormally (and unfairly) by taking money/ assets from them.

3. Decreased job motivation because of salary deductions - even if a desister gets a job, the practical, financial benefits of employment are undermined though salary deductions. In addition, the symbolic aspect of employment may also be negatively affected, because the state is signalling that desisters must continue to face consequences of their criminal conviction through salary deductions.

4. A feeling of inescapability - desistance demands significant effort, and being in debt has the double impact of increasing these demands while further constraining the desister's structural position over the long-term.

The state's imposition, surveillance and enforcement of significant and long-term debt raises important questions about when punishment really ends in Norway, about its legitimacy (given the experience of unfairness/ double punishment), and about how desistance may be prolonged to become a form of frozen, indeterminate liminality. Building on McNeill's (2018) malopticon, I note how desisters risk being seen badly (as debt repayment objects), being seen as bad (unentitled to own assets or earn more than a minimum subsistence) and being projected and represented as bad (leading to feeling unfairly treated, demotivated and trapped).

The project also puts a spotlight on the work of probation in Norway (Todd-Kvam 2020), an institution that has long fallen in the shadow of prisons, both in terms of resourcing and attention. I interviewed probation caseworkers in Oslo, who placed a strong emphasis on constructive relationships with their clients, whilst also noting that reintegration into Norwegian society is difficult. They put this down to lack of human and social capital and the challenges of navigating an increasingly remote and bureaucratic welfare system. This work highlights a dilemma in relational probation practice, in that relationships, which may have caused damage, distress and trauma, are also a means - and an end - to recovering from addiction and desisting from crime. From the caseworkers' perspective, a further dilemma is how to approach this without setting unrealistic expectations or engendering a sense of hopelessness or of being pathologised. Or, to frame it another way, neither expecting too much agency nor prolonging/deepening its absence. I suggest that these two dilemmas social relations as a cause and solution, and how much agency to expect - can perhaps usefully be understood as operating like a double helix through the client-caseworker relationship.

Regarding the experience of desistance more broadly, I and my co-author developed an analytical framework to help us understand desisters as active subjects navigating a complex terrain of psychological, relational and systemic processes (Todd-Kvam and Todd-Kvam 2021). 
The framework is intended to encompass both intra and inter-personal aspects of narrative identity and change. We then show that this framework can be used to explore how selfnarratives transform via a fine-grained analysis of the moments in which change starts, is maintained or is frustrated. The article also provides an empirical account of desistance in Norway as long-term and unfinalised, showing that even in a Scandinavian welfare state, the collateral damage of trauma, addiction and punishment can be significant, leading in some cases to an extended experience of liminality and welfare supplication.

Overall, I found the project to be very meaningful, and the persistence of many of those I met at the Network House in the face of serious obstacles to be inspiring.

\section{Key implications for practice}

- Debt and financial problems carry symbolic and psychological impact in addition to their practical consequences. Asking clients about these issues and being able to provide advice or signpost to other experts is important.

- Even with clients who appear stuck in what Shadd Maruna (Maruna 2001) might call a 'condemnation script', pay attention for so-called 'innovative moments' (Gonçalves, Cunha et al. 2011) where the client or those around them act against negative expectations (their own or others'). Such moments may provide an opportunity for client and caseworker to co-create new, more positive narratives.

- Linked to this, when considering how to help clients build self-belief, think about agency in terms of both connection and autonomy (Layton 2018).

\section{References}

Gonçalves, M. M., C. A. C. Cunha, A. P. Ribeiro, J. Salgado, M. Matos, A. Santos and I. Mendes (2011). Innovative moments in psychotherapy: dialogical processes in developing narratives. Dialogicality in Focus: Challenges to Theory, Method and Application. M. Märtsin, B. Wagoner, E.-L. Aveling, I. Kadianaki and L. Whittaker. New York, Nova Science Publishers: 173192.

Layton, L. (2018). Relational thinking: from culture to couch and couch to culture. Object relations and social relations. S. Clarke, H. Hahn and P. Hoggett, Routledge: 1-24.

Maruna, S. (2001). Making good: how ex-convicts reform and rebuild their lives. Washington, D.C., American Psychological Association.

McNeill, Fergus (2019), 'Mass supervision, misrecognition and the 'Malopticon.' Punishment \& Society, 21 (2), 207-30. https://doi. org/10.1177\%2F1462474518755137

Revold, M. K. (2015). Innsattes levekår 2014: Før, under og etter soning. Oslo, Kongsvinger, Statistisk Sentralbyrå. 47.

Todd-Kvam, J. (2019). 'An Unpaid Debt to Society: How 'Punishment Debt' Affects Reintegration and Desistance from Crime in Norway.' The British Journal of Criminology. https://doi.org/10.1093/bjc/azz024

Todd-Kvam, J. (2020). 'Probation practice, desistance and the penal field in Norway.' Criminology \& Criminal Justice. https://doi. org/10.1177\%2F1748895820953192

Todd-Kvam, J. and M. Todd-Kvam (2021). 'Talking Good: Analysing Narratives of Desistance in Norway.' The British Journal of Criminology. https://doi. org/10.1093/bjc/azab087 